\title{
More or less, and nothing in between
}

Daniele Rugo

Jean-Luc Nancy, Aurélien Barrau, What's These Worlds Coming To. Fordham University Press, 2014, 144pp, ISBN: 9780823263349

For the last three decades Jean-Luc Nancy has worked at a methodical and vigorous deconstruction of the world, driven by the affirmation that the world is without sense. This gesture insists instead on a return to the world from the neglect imposed on it by our philosophical and theological traditions. The demand emerging from Nancy's thought is that we ask again and again what the world wants of us and what we want of it.

Whilst the three Monotheisms declared their loyalty to a world beyond the world, to the opening of an otherworldly dimension that would rescue this world here, the rationalist trajectory confirmed and secured the completion and fulfilment of sense in a principle outside of this world.

The return to the world Nancy advocates is first of all a matter of retracing the tradition's unfolding, not in order to recapture its foundational gesture, but so to articulate what this unfolding passes on to us, so to receive, as patiently as possible the world's absence of sense. This expression should not be taken as designating the annihilation of sense, as if with it we were contemplating the closure of the world onto itself. Absence should be heard here according to a double connotation: the world was without its own sense, its meaning and destination being assigned to it from elsewhere; the world is now without the possibility of this reference, nothing is assigned to it anymore. Absence redoubles and names at once the process through which the world becomes insufficient and the process - already at work in the first through which whatever had filled in for this insufficiency comes to an end, leaving the world to itself.

The history of our world is the history of an absenting of sense. That sense is absent is the very mark of the philosophical-religious curve called the West. If philosophy as metaphysics established the absence of sense since its inception and permeated the Western trajectory with this very absence, then the 'death of God' is structurally embedded in our tradition rather than being a moment in the modern 
overcoming of religion. In other words, the accepted division between classical, Christian and modern periods would be misleading if constructed around three breaking points. Nancy rereads these periods stressing the essential permanence of an unfolding of absence and the continuity between theism and atheism. As a consequence his critique of this trajectory ultimately shows itself in places that are neither those of 'understanding' (the various rationalities and minor enlightenments we constantly encounter) nor those of 'religion' (rigid and compromised), but in what Nancy calls 'a passion' for this world without sense. This passion reacts to the intimidation reason prescribed for itself in order to deny its own religiosity, but also to deny in the same breath how that religion from which it so passionately wanted to break away and from which it so vigorously claimed its separation already harboured the newly proclaimed enlightenment.

The philosophical metaphysics that inaugurated theism did not resolve the question of the inaccessible and unconditioned - which myth embedded in the world through divine presences - but rather erected it to organizing principle. The divergence between polytheism and monotheisms is not that of a multitude opposed to a unity, but of presences opposed to a principle. Philosophical theism operates the dismissal of present divinities so that the measure of the divine is now its ontological distance from the world. This implies a further movement: once the world is deprived of the divine habitation of nature, this becomes a system organized by an absent principle. Man and god stop living in the world together. The places of the divine are emptied in favor of a unique principle that organizes the world without existing in it. It is at this juncture, in the substitution of a present divinity expressive of nature for the unity of an organizing principle detached from the world that theism and atheism share their premise. The transformation of our relation with the world is such that the inaccessible, once embedded in nature, becomes the order of the world. Reason's alogon projected outside of this world becomes its ground and controlling guarantor. Christianity assumes upon itself the philosophical idea of the unconditioned and creates a world out of it. The Christian world in other words is not another entity, but precisely that which cannot be qualified as an entity, not simply an other world, but another of any world. This excessive alterity is the heart of the world itself, but now assigned to its outside. In thinking that which exceeds it, reason takes it as its ground. The name God then becomes the metonymy for the excess of reason and for the 
affliction, call it madness, reason produces for itself. Monotheism is then an intrinsic condition of our civilization, rather than an alien protuberance. The tautological monism of the one God/principle governs our history.

It should then not come as a surprise that at the end of Adoration Nancy declares his departure from the question of Christianity. In fact it never was, one hears in that work, a matter of Christianity itself, but precisely of what in Christianity is not Christian, an anteriority that Christianity appropriates and relaunches.

This anteriority that Nancy individuates in the couple theism-atheism becomes in What's These Worlds Coming To? the problem of the 'one' and its 'order', or rather what the unfolding and self-surpassing of Western monology bequeath to us. Our world, this world without sense, is not then simply the explosion of the new, the event that deflagrates 'today', but the stretching out of a tension that has always been there, covered up within the metaphysical tautology and its displacement in God as organizing principle.

The task today is then to move beyond the one and order, according to a 'structional' logic. The gesture that Nancy here names 'struction' is not just a new formulation, but another tassel of a thought that has committed itself to nothing else but the world with its sense. Thought turns around and insists therefore on this one point: there is no one point, no 'this' one can point to and 'we can no longer be certain of a distinction between the world and us' (2). The withdrawal of the Gods, the departure of divine presences, has forced this dividing mark to oscillate about an equilibrium position that was never really secured its place (call the poles of this movement our sense of alienation from this world and our fear of engulfment by it). This double lack of positions - the world's and ours - becomes for Nancy the rhythmic rippling of the 'all together'.

The expression is undoubtedly imperfect, but the aim of this book is precisely that of tracing the end of those expressions whose reductive power captures the state of the world. There isn't one word for the world, and in particular the word 'one', behind which we could hear 'cosmos' and 'order', has lost sense. Or rather sense has shaken itself off its grip. Instead of reducing the significance of all things to the 'One' the suggestion is to follow its rhythm. The strategy that Nancy and his co-author, astrophysicist Aurélien Barrau, elaborate in this volume in order to accompany the 
world's rhythmicity is that of a movement between 'more' and 'less' that won't be reducible to the 'One' in between.

The 'One' itself since the beginning has announced nothing else than its own doubling, partition and self-overcoming. The logic of its motionless supremacy has always introduced also its very opposite: the one as 'the step itself, which divides itself and supplants and supplements its initiality on its own' (14). Excess has always belonged to the 'One' and to the philosophy that assigned itself to it by attempting to think the verb 'to be'. The unity of being that the One was supposed to resolve shows itself as "the unity of acting [...] which does not precede the "ones" of beings and does not occur to them either, but is, or rather acts, and takes note of their event and advent' (16). Being, understood according to the transitivity that Heidegger decisively disclosed, is therefore rhythmical. The rhythm of 'to be' is a push that shows itself always and everywhere; that divides and separates and therefore allows for relation and sharing. As soon as the 'One' took place it immediately exceeded itself towards 'the unity and unicity of pulsation, pulsion, impulse' (17). If there is unity then, it is the unity of a rhythm, of a constantly varying intensity, the generosity that removes itself from accumulation, the push that opens one thing to another, everything to everything. 'More than one' is then as a principle of differentiation, but a principle that is instantly deposed of its principality, ceding authority to profusion. However for this to happen, for the 'more than one' not to become again just a manifestation of the 'one and order', the rhythm has to reach immediately for its opposite, without allowing time for dialectical production. Barrau in the first response to Nancy, a response that true to its premise constantly puts the former text into play, shifts the weight of the proposal, both widening its scope and refracting its goal. 'More than one' can be seen as a most fertile meeting point between analytic and continental approaches (Goodman and Derrida in particular), between literal and literary values, but also between philosophy and physics. The latter in the attempt to perfect a cosmonomy has reached the stage where the 'only option is to accept all these theories as simultaneously correct though mutually incompatible' (37), since accepting one in view of a unitary truth of correctness would be the same as disregarding all of them. The 'more than one' then points to the world by pointing to an essential gap between our explanations of it. If this gap 'between the theories that caress the same aspect of the same real that gives rhythm to a version of the world, 
that forges itself together and is fractured from within' (38). In order to avoid the recoil of 'more' towards 'One' Barrau proposes to associate the movement the 'more than one' releases with 'less than one'. The rhythm oscillates from irreducible plurality to an equally irreducible 'not yet'. The impossibility of 'more' to return to the sovereign position of the 'One' (or to the One-position) has to be established straight away, so that 'more' falls back on and opens up to 'less', pure 'gestation' (39). There is more and there is less, gestation immediately turns into profusion, without ever crystallizing into unity and order. We do not start from nothing and move to 'one' before addition delivers us to 'more'. We do not start at all, the errance of sense takes over, and we err from 'less 'to' more without the basis of comparison ever installing itself between the two.

Nancy proceeds in this text less by following the urgency of a 'never before' and more by the patient reopening of what has always been the case. It so happens that the world today, what of the world today has never been experienced before is precisely the opening up and unfolding of what has always been taken for granted. The world is precisely caught in this: the unfolding does not happen through a linear chronology but in the collisions of a myriad of singular simultaneous moments. The concept of struction, introduced here as the 'uncoordinated simultaneity of things or beings' (49), is both 'an inevitable consequence of what has always been known and a radical upheaval of all the possible beings-in-the-world' (82).

Is struction then the name for the logic that traverses 'more' and 'less'? What is the programme that responds to the dual exhaustion of the one and order? Nancy begins to unravel the idea by referring to two competing and linked paradigms: construction and destruction. The belonging together of these two is in turn delimited by the belonging together of nature and technology. Technology, by supplanting and supplementing nature, from which it nonetheless emerges, constructs 'the very idea of this "nature" - its immanence, autofinality, and law of blossoming' (47). At the same time nature through technology deconstructs this very finality and reveals itself as devoid of an end. The collision and collaboration between technology and nature point then to the displacement of an ultimate end in favour of a constant proliferation. This shows itself in the exchange between means and ends, where "ends reveal themselves to be endless and where means, for their part, reveal themselves to be temporary ends that generate new possibilities' (45). The paradigm of construction 
thus leads straight away to its own overcoming, its energy overflows and dissolves into 'organic autonomy' (51). There where construction attempts to enhance and exploit nature's (apparent) inherent coordination, it produces the surpassing of enhancement itself (the end of constructivism) and discloses nature's uncoordinated proliferation of ends without end. The movement of modern construction, driven to perfect and refine means for the achievement of ends that are themselves imagined on the basis of available means, dissolves into a plurality that defies coordination.

What holds this plurality together? What kind of 'with' belongs to the 'all together' without order? Whilst in previous texts Nancy had operated a transformative appropriation of the Heideggerian 'with' that confirmed its existential character, here the term is stripped of its ontological qualification and assumes the purely categorial attribute of 'simple juxtaposition' (49). The only available cohesion is then that of a plurality of orders, where no ordering is valued more than any other: juxtaposition, fortuity, contingency become the tenets of this logic. 'Everything refers back to everything and thus everything shows itself through everything' (54), but without this 'everything' ever elevating itself above this dis-order, or shaping its mass into to a unitary principle.

Struction names then our world as the appearing together, before any meaningful togetherness, of all that appears/is. It is a togetherness that 'escapes the grasp of every construction' (52). Synchrony, perpetual inauguration, passage, 'ephemerality mixed with eternity' (53) are the operations according to which the brute obviousness of this heap rekindles the very possibility of sense. Nancy alerts us however that this brute obviousness is not a regression. It presents a further opportunity for thought. To think the world without neither beginning nor end, without neither destination nor intelligent design, but according to a permanent renewal of interest in what passes us by and therefore passes through us. It is a permanent reconfiguration that does not respond nor tends towards any assigned or divined figure. The irreducible fecundity of this opportunity implies however an equally great risk. Once we enter into struction every parcel of sense relaunches sense and the experience of the world altogether, onto limitlessness. This limitlessness can become self-destructive or simply find itself delimited and appropriated once again by capitalist accumulation, becoming a support for the engendering of an endless increase that 'displays neither flowering nor fruit' (46). Barrau in his second response reviews the horizon of limitlessness in order to 
chart possible springboards for a leap. Deleuze and Guattari are said to have touched this line of rupture, but without being able to become one with it (69), ultimately choosing Kosmos over Khaos. Heidegger is said to have sensed and expressed 'the necessity of extracting oneself from the constructional paradigm' (72), but remaining essentially dependent on nature's inherent order. It is then a matter of returning to the tradition, of reopening the origin. This is identified in Plato's Timaeus and in the orderly fortification this erected. Whilst this ode to order outlines the model for a perfectly organized universe, it also introduces the very displacement of this coordination: khora. The term, whose impossible translation and 'place' Derrida has put to work, is 'essential and yet destabilizing' (77). Because khora does not designate any known being it produces an essential troubling of Plato's twofold schema of one and order. Khora becomes here the formality without form for the impossible placing of sense in the regime of struction; it becomes the operation through which one can 'overthrow the dialectic of one and order, to let it get caught up in the game of its own exhaustion' (88). Sense becomes now what has to be but cannot be thought, contingent and proliferating. Sense is at the same time more and less: 'less' inasmuch as it does not obey any order and 'more' inasmuch as it does not gather itself into one ('more'). Structional sense, the sense of our world without sense, is then caught in a present that never accomplishes its own presence and yet pushes and pulsates. Our world is this very suspension, an unfinished leap; its rhythm and cadence are that of an 'always, but not yet'. 